\title{
Feasibility study of lecithin nanovesicles as spacers to improve the solubility of milk protein concentrate powder during storage
}

\author{
Nidhi Bansal $^{1}$ (D) Tuyen Truong ${ }^{1} \cdot{\text { Bhesh } \text { Bhandari }^{1}}^{1}$
}

Received: 27 May 2016 / Revised: 3 September 2016 / Accepted: 26 September 2016 / Published online: 2 November 2016

(C) INRA and Springer-Verlag France 2016

\begin{abstract}
Progressive loss of solubility of high-protein dairy powders is an unsolved issue in the dairy industry. Recent research has found that the solubility loss of powders is mainly contributed by the loss of dissociability of casein micelles from the parent powder particles. One of the ways of maintaining solubility of powders is to reduce the rate of development of association between casein micelles, by introducing spacers between the micelles. In this work, feasibility of using lecithin nanovesicles (produced by microfluidization) as spacers to improve solubility of protein-rich dairy powders was investigated. Nanostructured high-protein dairy powders were manufactured by adding 1, 5 and $10 \% \mathrm{w} / \mathrm{w}$ (of the total solids) nanovesicle $(\sim 82 \mathrm{~nm})$ dispersions to MPC80 suspensions and spray drying at $160{ }^{\circ} \mathrm{C}$ inlet and $75{ }^{\circ} \mathrm{C}$ outlet air temperature. The powders obtained were stored at 25 or $4{ }^{\circ} \mathrm{C}$ and 0.23 water activity and analysed for solubility loss during storage. The biggest effect of addition of lecithin nanovesicles on solubility was seen after 90 days of storage at $25{ }^{\circ} \mathrm{C}$. Addition of nanovesicles at a level as low as 1 and $5 \% w / w$ (of the total solids) could improve the solubility of MPC80 by 13 and $30 \%$, respectively during storage at $25{ }^{\circ} \mathrm{C}$ for 90 days. As expected, the solubility of all powders did not change much during 180 days of storage at $4{ }^{\circ} \mathrm{C}$ and remained above $90 \%$.
\end{abstract}

Keywords MPC solubility $\cdot$ Lecithin $\cdot$ Nanovesicles $\cdot$ Spacers $\cdot$ High-protein dairy powders

Bhesh Bhandari

b.bhandari@uq.edu.au

1 School of Agriculture and Food Sciences, The University of Queensland, St Lucia, Brisbane, QLD 4072, Australia 


\section{Introduction}

The two major groups of milk protein are caseins and whey proteins. The globular whey proteins $(20 \%$ of bovine milk protein) are soluble in water whereas the caseins $(80 \%$ of bovine milk protein) at $\mathrm{pH} 6.8$ exist in the form of colloidal micelles of size 20 to $500 \mathrm{~nm}$, in association with calcium phosphate (Horne 2011). These micelles are highly hydrated (average $3.7 \mathrm{~g}$ water.g casein protein) and have a large voluminosity $(4.4 \mathrm{~mL} \cdot \mathrm{g}$ protein) (De Kruif and Holt 2003). Since caseins are the major proteins in milk, the functional properties of the milk and milk products are highly dependent on the physical structure and chemical nature of the caseins. Any factor that influences the integrity and structure of casein micelles will affect the functional properties of the milk. One of the important functional properties of the dried milk and milk products is their solubility (Anema et al. 2006). The changes in the micellar integrity or structure of casein molecules occurring during processing and storage will influence the solubility of milk and milk products.

Spray drying is a common practice to convert liquid milk into powder form. Dehydration results into the formation of a dense particle structure with physically associated casein micelles (Mimouni et al. 2010a). The micelles are not only shrunk due to the loss of water but are also in close proximity with some spacing in between by other soluble serum phase components such as lactose, minerals, and whey proteins. Higher solids in the serum phase will keep the casein micelles further apart. However, in concentrated milk protein system, this serum part fraction remains low. Therefore, high-protein powder particles can be assumed as clusters of casein micelles, in which the casein micelles and the serum phase solids are associated with non-covalent forces such as hydrogen and electrostatic bonds and strong bonds such as van der Waals forces due to the small particulate size of casein micelles.

The clusters of casein micelles (in other words powder particles) should dissociate themselves during rehydration. It has been found that in the freshly dehydrated state, the powder is readily dissolved under standard rehydration conditions, indicating no strong bonds have been developed between the casein micelles (Anema et al. 2006). However, in aged powder, higher energy input level is required to solubilise the powder particles, such as higher temperature of the rehydration medium or shear forces (Havea 2006). In high-protein milk powder (e.g. MPC85) in which the amount of serum solids is low, there is a dramatic loss of solubility after 8 weeks of storage of powders (Mimouni et al. 2009). This indicates that over the time, the casein micelles associate more firmly. The image analysis of casein micelles has indicated that the micelles get more compact in the aged powder (Mimouni et al. 2010a). Thus, it is obvious that as the time progresses, the interaction between the casein micelles becomes more and more important. A complete loss of solubility can occur in high-protein milk powders within a year. In our previous research, we have found that the solubility loss of milk powder is mainly contributed by the loss of solubility of caseins (Mimouni et al. 2010b). Other researchers have also found that the insoluble material in MPC powders consists predominantly caseins (Havea 2006). Although, this is related to initially physical and then the chemical association of milk protein components, the actual mechanism has not been clearly understood yet. Many researchers have speculated that the later stage interaction could be hydrophobic and the cross-linking between the proteins could be initiated by other reactions such as Maillard reaction (Anema et al. 2006). 
One of the ways of maintaining solubility of milk powder could be to reduce the rate of development of association between casein micelles, by surface modification of micelles or introducing the spacer between the micelles. Considering the casein micelles as nanoparticles (within the size ranges $20-500 \mathrm{~nm}$ ), we can postulate that the presence of spacer particles that are smaller than the average size of casein micelles could lead to reduced interactions between the casein micelles. The potential nanoparticles to be added should not strongly interact with micelles and also not shrink or disintegrate during dehydration. These nanoparticles must be incorporated into the milk system prior to spray drying for them to act like spacers in the casein micelle aggregates (powder particles). The dairy or food grade materials that can be made in nanoparticulate forms are phospholipids and butterfat. Utilisation of spacer-enhanced protein solubility has not been previously reported in dairy industry.

Lipid vesicles are defined as 'spherical, self-closed structures composed of curved lipid bilayers which entrap part of the solvent, in which they freely float, into their interior' (Lasic 1993) or as 'closed, continuous bilayered structures made mainly of lipid and/or phospholipid molecules' (Mozafari et al. 2008). Nanovesicles are vesicles in nanometer size range (Mozafari et al. 2008). Lipid nanovesicles have been investigated extensively in pharmaceutical and cosmetics uses for drug carrier systems, pulmonary treatment and dermal applications (Pardeike et al. 2009; Xiang et al. 2007). In food-related applications, lipid nanovesicles have been used for encapsulating and delivering bioactive components and nutrients (Liu et al. 2012; Weiss et al. 2008).

Typical natural sources of phospholipids are soybean and egg. Milk fat globule membrane has also been used to produce lipid nanovesicles (Thompson and Singh 2006). Synthetic phospholipids can be prepared from glycerol or glycerol-3phosphocholine (GPC) from a plant or animal. Soybean lecithin is the typical plant source for GPC (van Hoogevest and Wendel 2014).

There are various ways to produce lipid nanovesicles: mechanical methods (microfluidization, ultrasonication, etc.); methods based on replacement of organic solvent(s) by aqueous media; methods based on detergent removal; methods based on size transformation and fusion and methods based on $\mathrm{pH}$ adjustment (Domb 2007). Among these preparation methods, a mechanical microfluidization technique provides many advantages in terms of scalability to batch production (Bachmann et al. 1993; Talsma et al. 1989), reproducibility of narrow size distribution (Masson 1989), handling higher lipid concentration over sonication (Talsma et al. 1989) and the preparation steps do not involve chemical substances, which is suitable for food application.

The aim of the study was to investigate the feasibility of using lecithin nanovesicles produced by microfluidization to improve the solubility of the protein-rich dairy powders. It was hypothesized that the nanovesicles, which are much smaller in size $(50-100 \mathrm{~nm})$ than the casein micelles $(20-500 \mathrm{~nm})$, will act as spacers between the casein micelles in the high-protein dairy powders. Addition of these nanoparticles was expected to minimise the intermicellar interactions and consequently facilitate the dissociation of casein micelles during the course of dissolution of powder particles. Thus, the nanostructured dairy powder was expected to exhibit higher solubility during storage than the conventional powders. 


\section{Materials and methods}

\subsection{Materials}

Ultralec ${ }^{\circledR}$ P (ADM, Australia), a deoiled soy lecithin produced by ultrafiltration process, was chosen to prepare nanovesicles. It has an effective hydrophilic-lipophilic balance (HLB) value of 7 and is readily dispersible in aqueous solutions. It contained only $2 \% \mathrm{w} / \mathrm{w}$ soybean oil and consequently a higher proportion of phospholipids compared to non-deoiled soy lecithin products.

\subsection{Preparation of nanovesicles}

Ultralec $\AA \mathrm{P}$ dispersion at a concentration of $5 \% \mathrm{w} / \mathrm{w}$ was prepared in $0.02 \mathrm{mg} \cdot \mathrm{L}^{-1}$ sodium azide solution and stirred at room temperature for $1 \mathrm{~h}$. Previous studies have suggested that adequate hydration of the soy lecithin dispersions before processing is an important factor in deciding the size and lamellarity of the nanoparticles (Sorgi and Huang 1996). One study has suggested hydrating the lecithin dispersion for $1 \mathrm{~h}$ before processing (Masson 1989). Hence, all dispersions in this study were hydrated at room temperature for $1 \mathrm{~h}$ before processing. The dispersions were passed through an airdriven microfluidizer for two passes (Model M-110 L, Microfluidics, USA) at $103 \mathrm{MPa}$ interaction chamber pressure. Based on preliminary results, it was found that these microfluidization conditions were sufficient to generate vesicles in nanosize range.

\subsection{Characterisation of nanovesicles}

\subsubsection{Size distribution}

The size distribution, the average hydrodynamic diameter (Z-Ave) and the polydispersity index (PDI) of the nanovesicles dispersions were measured at $25{ }^{\circ} \mathrm{C}$ using a nano series ZS Zetasizer (Malvern Instruments Ltd., Worcestershire, UK) using photon correlation spectroscopy (PCS). A medium viscosity of $0.8900 \mathrm{mPas}$, aqueous phase refractive index of 1.33 and typical lecithin refractive index of 1.459 were used. The samples were diluted 1:100 with distilled water before measurements.

\subsubsection{Electron microscopy}

Negative-staining transmission electron microscopy The nanovesicles produced were analyzed for morphology using negative-staining transmission electron microscopy. The nanovesicles were diluted approximately 1:20 with distilled water. One drop of the diluted sample was placed on a copper mesh for $2 \mathrm{~min}$. The sample was then combined with a drop of $2 \%$ ammonium molybdate and left for $30 \mathrm{~s}$ before the excess liquid was drawn off with a filter paper. The mesh was examined using a JEOL 1010 transmission electron microscope (JEOL, Tokyo, Japan) operating at $80 \mathrm{kV}$.

Thin-section transmission electron microscopy Thin sections of lecithin nanovesicles were prepared and viewed in a transmission electron microscope according to Ching et al. (2015). 


\subsection{Manufacture of nanostructured dairy powders}

High-protein milk powder (MPC 80) was dispersed in distilled water at a level of $11 \%$ total solids and rehydrated overnight at $4{ }^{\circ} \mathrm{C}$. Sodium azide was added to the MPC dispersion at a level of $0.02 \mathrm{mg} \cdot \mathrm{L}^{-1}$ to avoid any microbial growth. After overnight rehydration, nanovesicle preparation (Section 2.2) was added to MPC dispersion at various levels to achieve $0,1,5$ and $10 \%$ (w lecithin/w MPC solids) lecithin in MPC dispersions. The composition of various dispersions prepared is given in Table 1. The MPC suspension containing no added nanovesicles was considered the control samples. The samples were abbreviated as follows: MPC control $=\mathrm{MPC} ; \mathrm{MPC}+1 \%$ vesicles $=\mathrm{MPC}_{-} 1 ; \mathrm{MPC}+5 \%$ vesicles $=\mathrm{MPC} \_5$; and $\mathrm{MPC}+10 \%$ vesicles $=$ MPC_10. The MPC and nanovesicle mixture were thoroughly mixed and warmed to $35^{\circ} \mathrm{C}$ (which took about $30 \mathrm{~min}$ ) before spray drying. The mixture was then spray dried in the Buchi mini spray-dryer (B-290) at $160{ }^{\circ} \mathrm{C}$ inlet air temperature and $75{ }^{\circ} \mathrm{C}$ outlet air temperature. The powders obtained were immediately analysed for moisture content and stored at 25 or $4{ }^{\circ} \mathrm{C}$ and water activity $\left(\mathrm{a}_{\mathrm{w}}\right) 0.23$ up to 6 months. The $a_{\mathrm{w}}$ was maintained using a saturated solution of potassium acetate salt.

\subsection{Characterisation of nanostructured dairy powders during storage}

\subsubsection{Water activity and moisture analysis}

$A_{\mathrm{w}}$ of the powders was analysed at $25^{\circ} \mathrm{C}$ using an AquaLab Pre water activity meter (Graintec Scientific, Australia) with an accuracy of $\pm 0.01 \mathrm{a}_{\mathrm{w}}$. The meter was standardised with purified water $\left(1.000 \pm 0.003 \mathrm{a}_{\mathrm{w}}\right.$ at $\left.25{ }^{\circ} \mathrm{C}\right), 13.41 \mathrm{~mol} \cdot \mathrm{L}^{-1} \mathrm{LiCl}$ $\left(0.250 \pm 0.003 \mathrm{a}_{\mathrm{w}}\right.$ at $\left.25^{\circ} \mathrm{C}\right)$ and $8.57 \mathrm{~mol} \cdot \mathrm{L}^{-1} \mathrm{LiCl}\left(0.500 \pm 0.003 \mathrm{a}_{\mathrm{w}}\right.$ at $\left.25^{\circ} \mathrm{C}\right)$ each time before measurements. Moisture content of the powders was analysed by standard vacuum oven drying method to constant weight at $70{ }^{\circ} \mathrm{C}$.

\subsubsection{Solubility of nanostructured dairy powders}

All powder samples were stored for 6 months and the solubility was analysed at 0,30 , 60, 90 and 180 days. For measuring the solubility, the powders were rehydrated at $5 \%$ $w / w$ powder concentration in water according to (Mimouni et al. 2009). The suspension was maintained at a constant temperature of $30{ }^{\circ} \mathrm{C}$ using a water bath. Stirring was performed at constant speed (400 rpm) using an electric overhead mixer (RW20, IKA,

Table 1 Water activity of nanostructured powders during storage at $25^{\circ} \mathrm{C}$

\begin{tabular}{llllll}
\hline Sample & $\begin{array}{l}\text { MPC solids } \\
(\mathrm{g})\end{array}$ & $\begin{array}{l}\text { Lecithin } \\
(\mathrm{g})\end{array}$ & $\begin{array}{l}\text { Total solids in feed } \\
(\mathrm{g})\end{array}$ & $\begin{array}{l}\text { Lecithin/ w of milk } \\
\text { solids }(\%)\end{array}$ & $\begin{array}{l}\text { Lecithin/ w of total } \\
\text { solids }(\%)\end{array}$ \\
\hline MPC & 330 & 0 & 330 & 0 & 0 \\
MPC_1 & 330 & 3.3 & 333.3 & 1 & 0.99 \\
MPC_5 & 330 & 16.5 & 343.5 & 5 & 4.8 \\
MPC_10 & 330 & 33 & 363 & 10 & 9.09 \\
\hline
\end{tabular}


Staufen, Germany) and 4-bladed propeller stirrer of 50-mm diameter (R 1342, IKA, Staufen, Germany) for $30 \mathrm{~min}$. After $30 \mathrm{~min}$, the suspension was immediately centrifuged at $1000 \times g$ for $10 \mathrm{~min}$. The supernatant obtained after centrifugation was filtered under vacuum using a glass fibre filter $(0.6 \mu \mathrm{m}$, GA-55, Advantec). The filtrate and the original suspension were analysed for total solid content by overnight vacuum-oven drying at $70{ }^{\circ} \mathrm{C}$. The solubility of each sample was calculated as follows:

Solubility $(\%)=($ total solids per $\mathrm{g}$ of filtrate/total solids per $\mathrm{g}$ of suspension $) * 100$

\subsection{Statistical analysis}

Analysis of variance on the data was performed by one-way ANOVA with Fisher post hoc test at 95\% confidence level, using the statistical analysis software Minitab 17. All results are the mean of triplicate analyses. Graphs (where applicable) were created using SigmaPlot 13.0.

\section{Results and discussion}

\subsection{Characterisation of nanovesicles}

The average hydrodynamic diameter of the lecithin nanovesicles prepared by microfluidization at $103 \mathrm{MPa}$ and two passes was $82.25 \pm 2.11 \mathrm{~nm}$. A typical particle size distribution of nanovesicles dispersions is depicted in Fig. 1. The particle size distribution represented a monomodal distribution with a narrow size range in all replications. The polydispersity index of the distributions was $0.27 \pm 0.01$. These results are similar to those reported in literature (Thompson et al. 2006b; Thompson et al. 2006a).

The morphology of the nanovesicles was analysed using electron microscopy. The results of a typical negative transmission electron micrograph are given in Fig. 2. The nanovesicles appeared to be well-contoured discrete spherical particles with majority of the particles well below $100 \mathrm{~nm}$ in size. A few particles appeared to be connected by bridges which could be artefacts from sample preparation during negative-staining TEM. A thin-section TEM was also conducted to confirm the structure and lamellarity of the nanovesicles. The micrographs obtained from this technique conclusively showed that the particles produced were mostly bi-lamellar vesicles (highlighted by the black arrows in the micrograph) of less than $100-\mathrm{nm}$ size (Fig. 3). These micrographs are typical of lecithin nanovesicles produced by microfluidization similar to the ones reported by other researchers (Thompson et al. 2006a; Thompson et al. 2006b).

\subsection{Properties of nanostructured powders during storage}

The moisture content and $\mathrm{a}_{\mathrm{w}}$ of the nanostructured powders were analysed at $0,15,30$ and 180 days of storage. It was found that at any given storage time, there were no significant differences in moisture content and $\mathrm{a}_{\mathrm{w}}$ of the powders containing different 


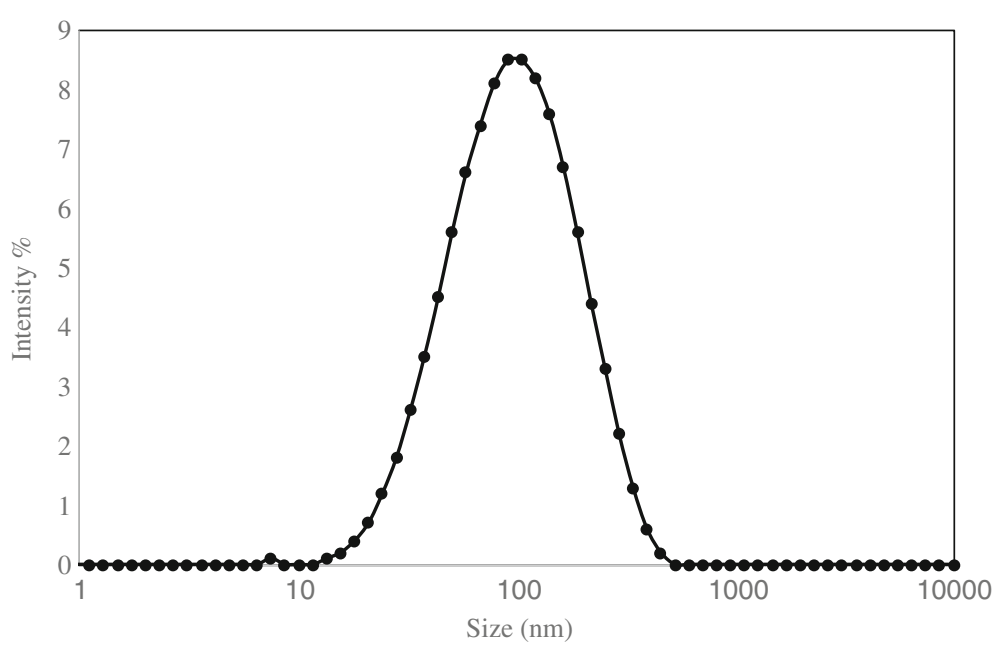

Fig. 1 Typical particle size distribution of the lecithin nanovesicles prepared by microfluidization at 15000 Psi and two passes

amounts of nanovesicles (Table 2). Similarly, the moisture content and $\mathrm{a}_{\mathrm{w}}$ of any of the nanostructured powders did not change significantly during storage (Table 2). This

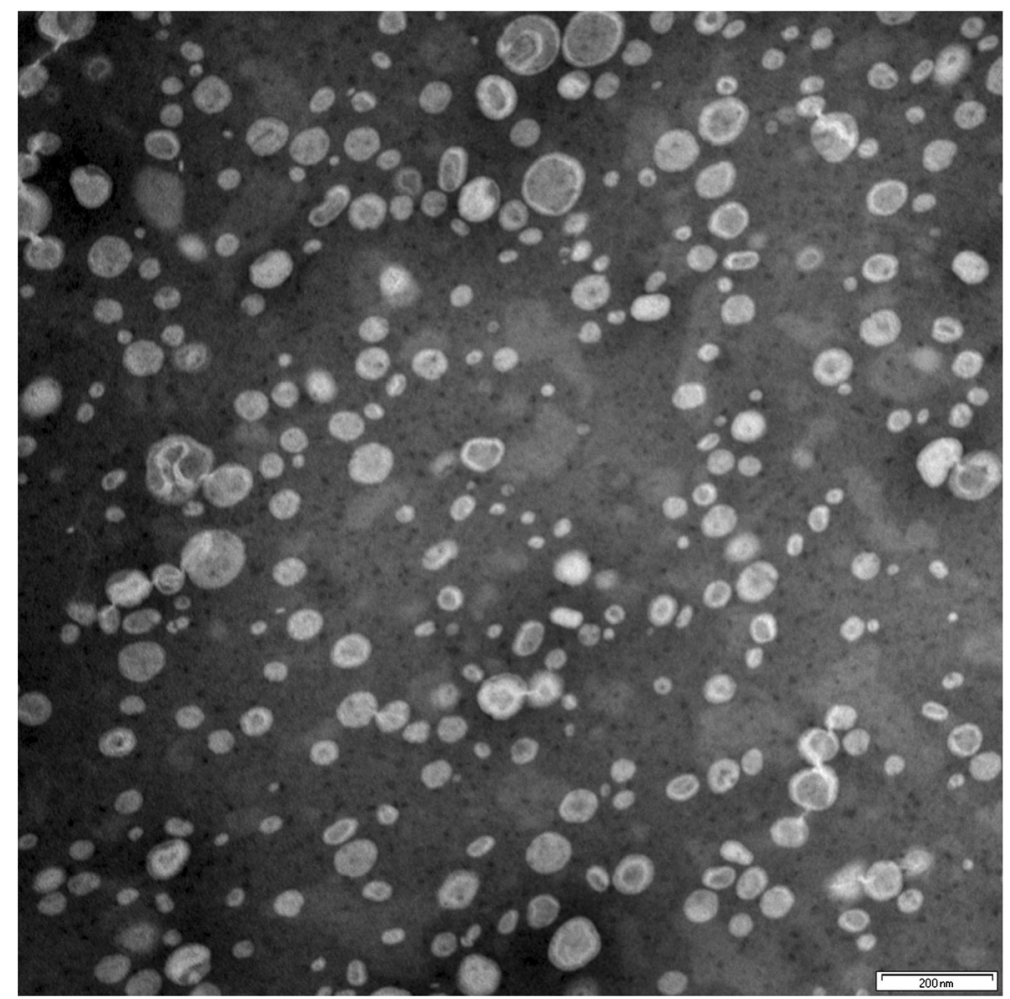

Fig. 2 Electron micrograph of a typical nanovesicle preparation. The bar at the bottom of the micrograph represents $200 \mathrm{~nm}$ 


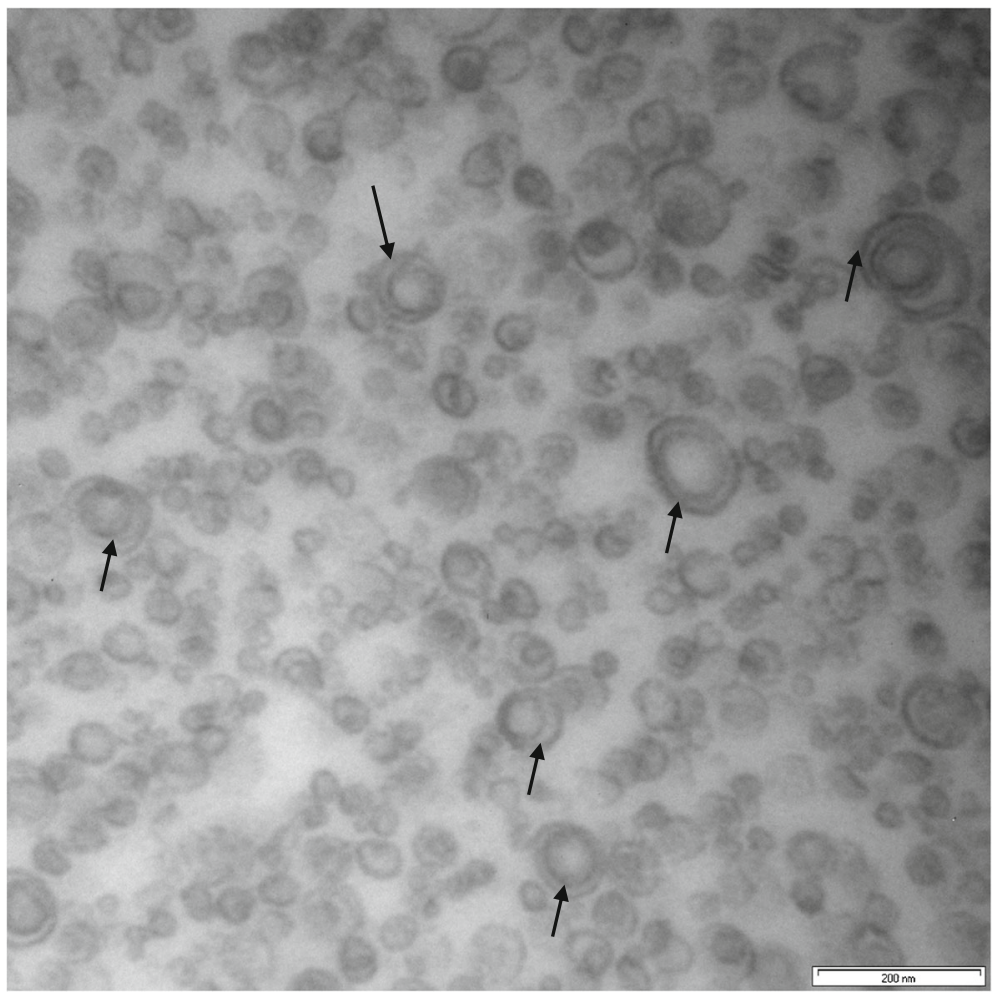

Fig. 3 Thin section electron micrograph of a typical nanovesicle preparation. The bar at the bottom of the micrograph represents $200 \mathrm{~nm}$. Bi-lamellarity of vesicles is highlighted by the black arrows in the micrograph

indicated that potential physico-chemical change during storage could not be signified by these two parameters.

\subsection{Solubility of nanostructured powders during storage}

Solubility of nanostructured powders stored at 4 and $25{ }^{\circ} \mathrm{C}$ was measured at $0,30,60$, 90 and 180 days of storage. Figure 4 shows changes in solubility of nanostructured powders stored at $25{ }^{\circ} \mathrm{C}$. At day 0 , there was no significant difference $(P>0.05)$ between the solubility values of MPC, MPC_1 and MPC_10. However, MPC_5 showed significantly $(P<0.05)$ higher solubility than MPC and MPC_1 (Fig. 4).

After 30 days of storage, solubility of MPC 5 was still significantly higher $(P<0.05)$ than MPC and MPC_1. However, the biggest effect of addition of lecithin nanovesicles on solubility of high-protein dairy powders was seen after 90 days of storage at $25^{\circ} \mathrm{C}$. At day 90, all nanostructured powders had significantly $(P<0.05)$ higher solubility than the control MPC; the solubility of MPC 5 and MPC 10 was $>80 \%$, while the solubility of MPC was only $63.2 \%$. There was an about $31 \%$ loss of solubility of the control MPC powder, whereas the solubility of MPC_5 and MPC_10 decreased only by about $15 \%$. The results showed that an addition of nanovesicles at a level as low as $1 \%$ could improve the solubility of MPC 80 by $13 \%$ during storage at $25{ }^{\circ} \mathrm{C}$ for 90 days, while addition of nanovesicles at $5 \%$ increased the solubility by $30 \%$ (Fig. 4). 
Table 2 Moisture content (\%) of nanostructured powders during storage at $25^{\circ} \mathrm{C}$

\begin{tabular}{|c|c|c|c|c|c|c|c|c|}
\hline \multirow[t]{2}{*}{ Sample } & \multicolumn{4}{|l|}{$A_{w}$} & \multicolumn{4}{|c|}{ Moisture content $(\%)$} \\
\hline & 0 day & 15 days & 30 days & 180 days & 0 day & 15 days & 30 days & 180 days \\
\hline MPC & $0.29 \pm 0.01$ & $0.29 \pm 0.01$ & $0.31 \pm 0.03$ & $0.26 \pm 0.01$ & $5.8 \pm 2.4$ & $5.8 \pm 0.5$ & $5.3 \pm 0.2$ & $5.9 \pm 1.1$ \\
\hline $\mathrm{MPC}_{-} 1$ & $0.29 \pm 0.01$ & $0.28 \pm 0.03$ & $0.29 \pm 0.01$ & $0.28 \pm 0.01$ & $4.7 \pm 0.7$ & $4.8 \pm 0.2$ & $5.2 \pm 1.1$ & $4.4 \pm 2.1$ \\
\hline MPC_5 & $0.28 \pm 0.02$ & $0.29 \pm 0.01$ & $0.28 \pm 0.01$ & $0.26 \pm 0.01$ & $4.7 \pm 1.0$ & $5.4 \pm 0.5$ & $5.9 \pm 1.4$ & $5.4 \pm 0.4$ \\
\hline MPC_10 & $0.3 \pm 0.03$ & $0.28 \pm 0.03$ & $0.28 \pm 0.01$ & $0.28 \pm 0.01$ & $4.5 \pm 0.1$ & $4.0 \pm 0.8$ & $4.9 \pm 0.3$ & $4.3 \pm 1.0$ \\
\hline
\end{tabular}

Values are means and standard deviations $(n=6)$; no statistically significant differences were found between means within all columns and rows of one measurement parameter (Fisher, $P<0.05$ )

After 180 days of storage at $25^{\circ} \mathrm{C}$, no statistically significant differences were found in the solubility of powders with different treatments. But this could be due to the large standard deviations observed between the three replicates (Fig. 4). Individually, in all three replicates, solubility showed an increasing trend of $>15 \%$ for MPC_5 and MPC_10 compared to the solubility of MPC and MPC_1. Throughout storage, there were no significant differences in solubility of MPC_5 and MPC_10 (Fig. 4), suggesting that $5 \%$ addition of nanovesicles was sufficient to improve the solubility of MPC80.

As expected, the solubility of powders did not change much during 180 days of storage at $4{ }^{\circ} \mathrm{C}$ and remained above $90 \%$ (Fig. 5). At day 0 and 30, the solubility of MPC_5 was marginally higher than that of MPC and MPC_1, but these differences levelled off by day 60 (Fig. 5).

Considering the casein micelles as nanoparticles (within the size ranges 20-500 nm), and assuming that the nanovesicles retain their structure after mixing with the MPC

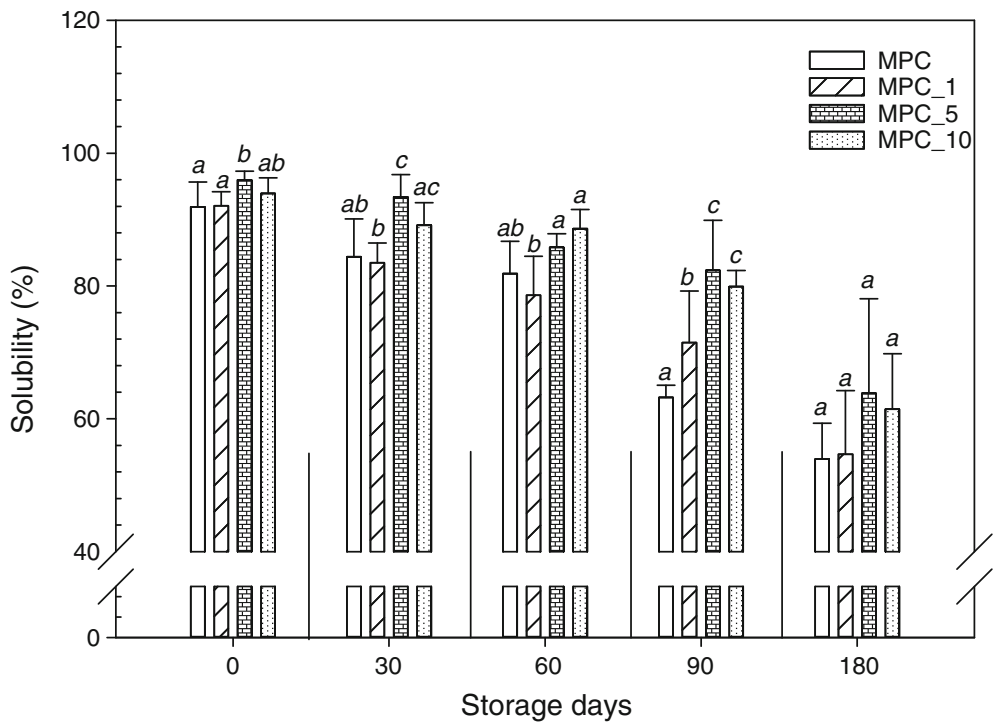

Fig. 4 Solubility of nanostructured powders stored at $25{ }^{\circ} \mathrm{C}$ for 180 days. Bars are means and standard deviations $(n=6)$. Means at any storage day that do not share a letter are significantly different (Fisher, $P<0.05$ ) 


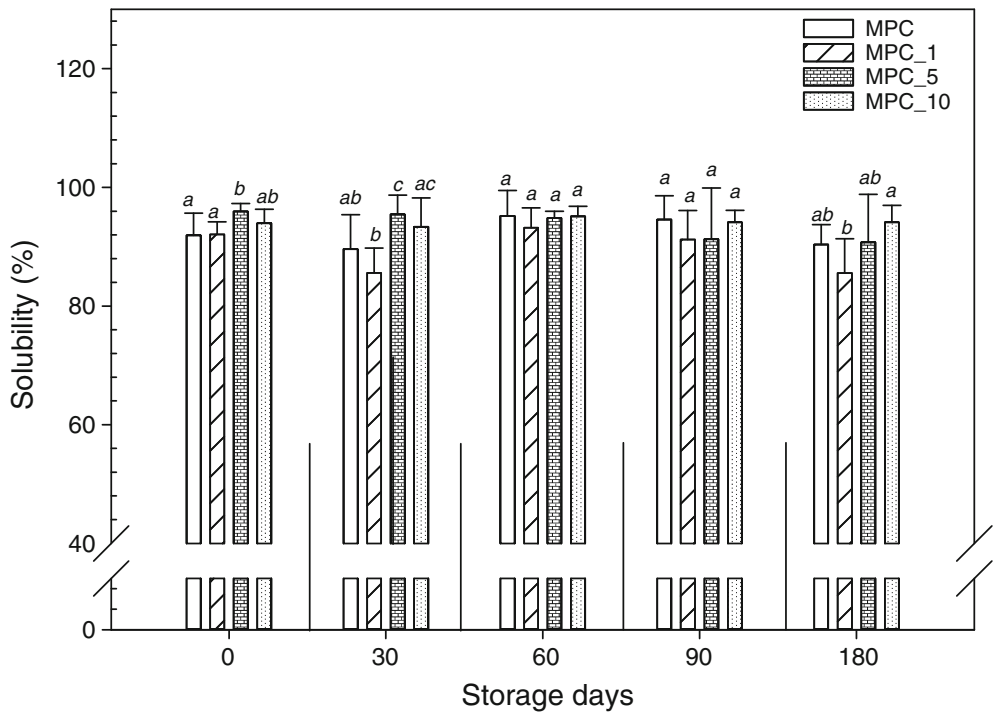

Fig. 5 Solubility of nanostructured powders stored at $4{ }^{\circ} \mathrm{C}$ for 180 days. Bars are means and standard deviations $(n=6)$. Means at any storage day that do not share a letter are significantly different (Fisher, $P<0.05)$

solution before and after drying, we can postulate that the presence of spacer particles that are smaller than the average size of casein micelles could lead to reduced interaction between the casein micelles according to the hypothesis diagram shown in Fig. 6. No such work has been reported in literature so far. Therefore, this work contributes to new knowledge on the application of lecithin nanovesicles in the dairy powder manufacturing industry.

The use of soy lecithin $(0.1-0.4 \%)$ to improve the wettability of full cream milk powders and other dairy powders has been practiced for many decades (Kim et al. 2009; Westergaard 2004). In this approach, lecithin is commonly added to the powder at the fluidised bed stage, immediately after spray drying. Direct lecithination of dairy powders (by lecithin addition to milk prior to drying) for confectionery applications has also been reported (Millqvist-Fureby and Smith 2007), although so far this does not seem to have been developed industrially as a reliable or cost-effective means of delivering functional polar lipids to the powder surface. These additions follow

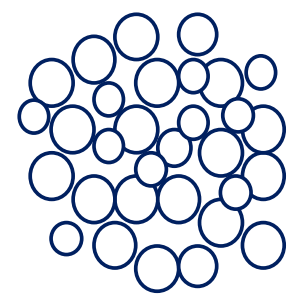

O
Casein micelles $(20-500 \mathrm{~nm})$

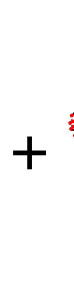

$\because$
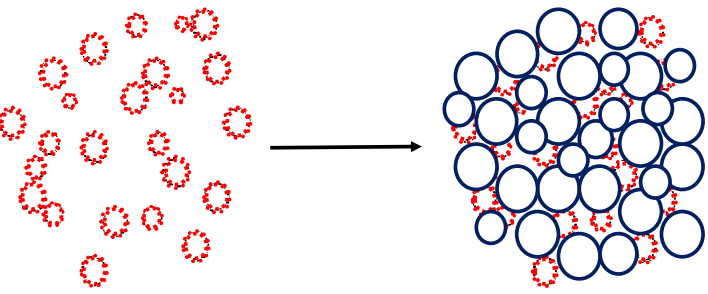

Nano-structured dairy powder

Fig. 6 Hypothesis diagram of added nanoparticles as spacers to improve solubility of nanostructured highprotein dairy powders 
relatively simple protocols and do not involve the preparation of vesicles. Thus, the lecithination principle used in this study is entirely different and innovative. In addition, this work deals not only with the immediate functional characteristics of freshly manufactured powders but also with the progressive loss of solubility of dairy powders over storage.

\section{Conclusions}

In this study, high-protein nanostructured dairy powders were prepared by incorporating lecithin nanovesicles into MPC80 before spray drying. The loss of solubility during storage of these powders was characterised. After 90 days of storage at $25{ }^{\circ} \mathrm{C}$, all nanostructured powders had significantly higher solubility than the control powder. Addition of nanovesicles at a level as low as $1 \%$ could improve the solubility of MPC 80 by $13 \%$. For a larger increase in powder solubility ( $30 \%$ increase), addition of nanovesicles at a higher concentration (5\%) was required. Even after 180 days of storage at $25{ }^{\circ} \mathrm{C}$, powder solubility showed an increasing trend of $>\sim 15 \%$ at 5 and $10 \%$ addition level of nanovesicles. These results conclusively show that addition of nanovesicles as spacers between casein micelles could have a positive impact on solubility of high-protein dairy powders during storage. Being a feasibility study, focussed powder parameters were characterised in this study. A more comprehensive future study on detailed material properties, microstructure characterisation, spacial distribution of the lecithin vesicles in the dried powders and functional properties of the nanostructured powders other than solubility will be undertaken. Lecithin nanovesicles could potentially also be used to delay the interaction between proteins in other highprotein dry food systems. This will need further investigation.

Acknowledgments This project is funded by Dairy Innovation Australia Limited (Grant Number 10104B).

\section{References}

Anema SG, Pinder DN, Hunter RJ, Hemar Y (2006) Effects of storage temperature on the solubility of milk protein concentrate (MPC85. Food Hydrocoll 20(2-3):386-393. doi:10.1016/j.foodhyd.2005.03.015

Bachmann D, Brandl M, Gregoriadis G (1993) Preparation of liposomes using a Mini-Lab 8.30 H highpressure homogenizer. Int J Pharm 91(1):69-74. doi:10.1016/0378-5173(93)90422-C

Ching SH, Bhandari B, Webb R, Bansal N (2015) Visualizing the interaction between sodium caseinate and calcium alginate microgel particles. Food Hydrocoll 43(0):165-171. doi:10.1016/j.foodhyd.2014.05.013

De Kruif CG, Holt C (2003) Casein micelle structure, functions and interactions. In: Fox PF, McSweeney PLH (eds) Advanced dairy chemistry_-1 proteins: part a / part b. Springer US, Boston, MA, pp. 233-276. doi:10.1007/978-1-4419-8602-3_5

Domb AJ (2007) Nanoparticles for pharmaceutical applications, vol 16., vol Book, Whole. American Scientific Publishers, Stevenson Ranch, Calif

Havea P (2006) Protein interactions in milk protein concentrate powders. Int Dairy J 16(5):415-422. doi:10.1016/j.idairyj.2005.06.005

Horne DS (2011) Milk proteins | casein, micellar structure A2-Fuquay. In: John W (ed) Encyclopedia of dairy sciences (second edition). Academic Press, San Diego, pp. 772-779. doi:10.1016/B978-0-12374407-4.00431-3 
Kim EHJ, Chen XD, Pearce D (2009) Surface composition of industrial spray-dried milk powders. 1. Development of surface composition during manufacture. J Food Eng 94(2):163-168. doi:10.1016/j. jfoodeng.2008.09.021

Lasic DD (1993) Liposomes: from physics to applications. Elsevier, Amsterdam

Liu GY, Wang JM, Xia Q (2012) Application of nanostructured lipid carrier in food for the improved bioavailability. Eur Food Res Technol 234(3):391-398. doi:10.1007/s00217-011-1645-z

Masson G (1989) Characterization of small lipid vesicles prepared by microfluidization. In: Bothorel P, Dufourc EJ (eds) Trends in Colloid and Interface Science III Steinkopff, Darmstadt, pp 49-51. doi:10.1007/BFb0116185

Millqvist-Fureby A, Smith P (2007) In-situ lecithination of dairy powders in spray-drying for confectionery applications. Food Hydrocoll 21(5-6):920-927. doi:10.1016/j.foodhyd.2006.11.009

Mimouni A, Deeth HC, Whittaker AK, Gidley MJ, Bhandari BR (2009) Rehydration process of milk protein concentrate powder monitored by static light scattering. Food Hydrocoll 23(7):1958-1965. doi:10.1016/j. foodhyd.2009.01.010

Mimouni A, Deeth HC, Whittaker AK, Gidley MJ, Bhandari BR (2010a) Investigation of the microstructure of milk protein concentrate powders during rehydration: alterations during storage. J Dairy Sci 93(2):463472. doi:10.3168/jds.2009-2369

Mimouni A, Deeth HC, Whittaker AK, Gidley MJ, Bhandari BR (2010b) Rehydration of high-proteincontaining dairy powder: slow- and fast-dissolving components and storage effects. Dairy Sci \& Technol 90(2):335-344. doi:10.1051/dst/2010002

Mozafari MR, Khosravi-Darani K, Borazan GG, Cui J, Pardakhty A, Yurdugul S (2008) Encapsulation of food ingredients using nanoliposome technology. Int J Food Prop 11(4):833-844. doi:10.1080 /10942910701648115

Pardeike J, Hommoss A, Müller RH (2009) Lipid nanoparticles (SLN, NLC) in cosmetic and pharmaceutical dermal products. Int J Pharm 366(1-2):170-184. doi:10.1016/j.ijpharm.2008.10.003

Sorgi FL, Huang L (1996) Large scale production of DC-Chol cationic liposomes by microfluidization. Int J Pharm 144(2):131-139. doi:10.1016/S0378-5173(96)04733-3

Talsma H, Özer AY, Lv B, Crommelin DJA (1989) The size reduction of liposomes with a high pressure homogenizer (microfluidizer ${ }^{\mathrm{TM}}$ ). Characterization of prepared dispersions and comparison with conventional methods. Drug Dev Ind Pharm 15(2):197-207. doi:10.3109/03639048909040205

Thompson AK, Singh H (2006) Preparation of liposomes from milk fat globule membrane phospholipids using a microfluidizer. J Dairy Sci 89(2):410-419. doi:10.3168/jds.S0022-0302(06)72105-1

Thompson AK, Haisman D, Singh H (2006a) Physical stability of liposomes prepared from milk fat globule membrane and soya phospholipids. J Agric Food Chem 54(17):6390-6397. doi:10.1021/jf0605695

Thompson AK, Hindmarsh JP, Haisman D, Rades T, Singh H (2006b) Comparison of the structure and properties of liposomes prepared from milk fat globule membrane and soy phospholipids. J Agric Food Chem 54(10):3704-3711. doi:10.1021/jf052859b

van Hoogevest P, Wendel A (2014) The use of natural and synthetic phospholipids as pharmaceutical excipients. Eur J Lipid Sci Technol 116(9):1088-1107. doi:10.1002/ejlt.201400219

Weiss J, Decker EA, McClements DJ, Kristbergsson K, Helgason T, Awad T (2008) Solid lipid nanoparticles as delivery systems for bioactive food components. Food Biophysics 3(2):146-154. doi:10.1007/s11483008-9065-8

Westergaard V (2004) Milk powder technology. Niro A/S, Copenhagen

Xiang Q-y, Wang M-t, Chen F, Gong T, Y-1 J, Z-r Z, Huang Y (2007) Lung-targeting delivery of dexamethasone acetate loaded solid lipid nanoparticles. Arch Pharm Res 30(4):519-525. doi:10.1007/bf02980228 